\title{
Pros and cons of specialised care in bipolar disorder: an international perspective $^{\dagger}$
}

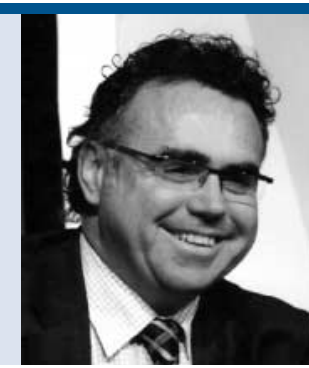

Eduard Vieta

\section{Summary}

Highly specialised care may have both pros and cons. Centralised expert treatment may be more effective than standard community care for bipolar disorder. Rather than trying to solve the false dichotomy between specialised $v$. community care, the rational integration of both approaches may enhance quality of care and cost-effectiveness.

\section{Declaration of interest}

E.V. leads a specialist bipolar disorder care unit at a public university hospital in Catalonia, Spain.
Eduard Vieta is Professor of Psychiatry, Head of the Department and the Director of the Bipolar Disorders Program of the Hospital Clinic at the University of Barcelona in Catalonia, Spain. He is the current Director of the Bipolar Research Program at the Spanish Research Network on Mental Diseases (CIBERSAM). His research focuses on the neurobiology, epidemiology and treatment of bipolar disorder.

\section{Specialisation in psychiatry}

Specialisation is inherent to the progress of medicine. A century ago, the amount of knowledge and skills that were required to work as a physician was small enough to cover practically all medical conditions. Nowadays, there are specialists within specialties (do not ask a neurologist who works in the field of Alzheimer's disease to decide on the treatment of a patient with epilepsy). Obviously, general practitioners are necessary because they have the broader view of most common and non-severe conditions, and because they appropriately act as the gatekeepers for specialised care. A system based on specialists only would go nowhere. Psychiatry is not an exception, and there is a need for both generalists and specialists. Patients with the most common conditions and who are mild-to-moderately ill may well be diagnosed and treated by general psychiatrists, but for severe, complex and unusual cases, more specialised experts are and will be necessary. The current state of affairs makes it impossible for one doctor to be truly knowledgeable about the management of, for example, a severe case of anorexia nervosa, an old man with alcoholism and pathological gambling, a complex case of schizophrenia with obsessive-compulsive features, and a patient with rapid-cycling bipolar disorder. Child psychiatry and addiction psychiatry are now accepted in many countries as subspecialties within psychiatry, and several others may be in the near future.

One of the barriers to specialised care is cost. Specialised care is generally more expensive than community care and is not always more effective. In the context of public healthcare, specialisation has emerged in tertiary hospitals as a way to deal with complex conditions and technological progress; in the private sector, there may be specific facilities that have evolved into

†See pp. 212-219, this issue. specialised-care settings for a given condition or technique. Specialisation may be cost-effective in the public sector as long as the most appropriate level of care (i.e. tertiary $v$. community) is provided for a given case. Psychiatry may be especially vulnerable to some policies that downgrade the importance of medical skills, including diagnosis, treatment and monitoring. In many instances, this has resulted in services that are better suited to delivering non-specific, psychosocial support rather than a process of thorough, broad-based diagnostic assessment with formulation of aetiology, diagnosis and prognosis followed by specific treatments aimed at recovery with maintenance of functioning. ${ }^{1}$ Although everybody would agree that some degree of expertise and experience may be necessary to pilot a plane, psychiatric interventions and treatments are often viewed as low-tech, unspecific and unsophisticated instruments to merely calm people who are mentally ill. However, there is no alternative to the increasing introduction of technology in psychiatry, and many of the concerns about costs are the result of discrimination regarding people with mental illness over those who have 'socially friendly' conditions such as cancer or even dementia.

\section{Specialised care in bipolar disorder}

In the specific case of bipolar disorder, it has a complex phenotype with high external validity that requires a broad knowledge of psychopathology, neuropsychology, psychopharmacology and psychotherapy. These, and other reasons, have prompted some authors to advocate that bipolar disorder is 'the heartland' of psychiatry. ${ }^{2}$ In this issue of the Journal, Kessing et al $^{3}$ report that treatment in a specialised mood disorder clinic early in the course of bipolar disorder substantially reduces readmissions to hospital and increases satisfaction with care compared with standard community care. Strengths of the study include the randomised design and the practical relevance of the question addressed. This study supports specialised management of patients with bipolar disorder.

What would be the cons of giving too much support to specialised care as opposed to traditional community care? One risk may be fragmentation of care, especially if the setting for specialised care is a tertiary hospital that may be far away from patients' homes. Too much specialisation may also result in gaps in overall care if not properly organised, and may not guarantee the focus on functional recovery. ${ }^{4}$ Another concern may be cost. 
However, bipolar disorder units may actually provide better continuity of care if the same patient is seen by the same team regardless of the setting, and they may also carry advantages in terms of education and research. ${ }^{5-7}$ Hence, the European Union seventh framework programme has sponsored a network of expert centres called ENBREC (Euoropean Network of Bipolar Research Expert Centres), aimed at developing common tools for the assessment and management of bipolar disorder across Europe. Obviously, specialised centres may well be better suited for research and training on the specific condition of their expertise compared with community centres. Moreover, sophisticated interventions that have been designed by experts from referral centres, such as group psychoeducation or functional remediation, may be cost-effective and may be implemented in all sorts of settings if therapists are adequately trained. ${ }^{8-9}$ Hence, the key to getting the best from both specialised and community care may be to enable their rational integration into existing psychiatric services, ${ }^{10}$ and choosing the right setting for the right patient at the right moment - perhaps not easy, but feasible and highly desirable.

Eduard Vieta, MD, PhD, Hospital Clinic, University of Barcelona, IDIBAPS, CIBERSAM, Barcelona, Catalonia, Spain

Correspondence: Eduard Vieta, Hospital Clinic, 170 Villarroel St, 08036 Barcelona, Catalonia, Spain. Email: evieta@clinic.ub.es

First received 22 Nov 2012, accepted 26 Nov 2012

\section{References}

1 Craddock N, Antebi D, Attenburrow MJ, Bailey A, Carson A, Cowen P, et al. Wake-up call for British psychiatry. Br J Psychiatry 2008; 193: 6-9.

2 Goodwin GM, Geddes JR. What is the heartland of psychiatry? Br J Psychiatry 2007; 191: 189-91.

3 Kessing LV, Hansen HV, Hvenegaard A, Christensen EM, Dam H, Gluud C, et al. Treatment in a specialised out-patient mood disorder clinic $v$. standard out-patient treatment in the early course of bipolar disorder: randomised clinical trial. Br J Psychiatry 2013; 202: 212-9.

4 Rosa AR, Reinares M, Amann B, Popovic D, Franco C, Comes M, et al. Six-month functional outcome of a bipolar disorder cohort in the context of a specialized-care program. Bipolar Disord 2011; 13: 679-86.

5 Vieta E. Tertiarism in psychiatry: Barcelona Clínic bipolar disorders programme. Rev Psiquiatr Salud Ment 2011; 4: 1-4.

6 Vieta E. Bipolar units and programmes: are they really needed? World Psychiatry 2011; 10: 152.

7 Henry C, Etain B, Mathieu F, Raust A, Vibert JF, Scott J, et al. A French network of bipolar expert centres: a model to close the gap between evidence-based medicine and routine practice. J Affect Disord 2011; 131: 358-63.

8 Scott J, Colom F, Popova E, Benabarre A, Cruz N, Valenti M, et al. Long-term mental health resource utilization and cost of care following group psychoeducation or unstructured group support for bipolar disorders: a cost-benefit analysis. J Clin Psychiatry 2009; 70: 378-86.

9 Martínez-Arán A, Torrent C, Solé B, Bonnín CM, Rosa AR, Sánchez-Moreno J, et al. Functional remediation for bipolar disorder. Clin Pract Epidemiol Ment Health 2011; 7: 112-6.

10 Lyndon RW. The role of specialised units in the treatment of affective disorders. Aust N Z J Psychiatry 1991; 25: 491-8.

Love and loss are two sides of the same coin. Patterns of attachment to parents in childhood predict how adults will respond to losses in adult life. Avoidant attachments predict avoidance of closeness, delayed grief and self-reproaches, anxious attachments predict severe and protracted grief, and disorganised attachments predict helplessness and depression. All of these increase vulnerability following unexpected or otherwise traumatic losses. There is no single counselling or therapy that provides a catch-all solution. In the UK, Cruse Bereavement Care provides a flexible response to most problems, but cognitive-behavioural therapy tailored to specific problems may be needed too. 